\title{
Article
}

\section{Emergency department nurse's attitudes towards patients who self-harm: A meta- analysis}

Rayner, Gillian, Blackburn, Joanna, Edward, Karen-leigh, Stephenson, John and Ousey, Karen

Available at http://clok.uclan.ac.uk/24804/

Rayner, Gillian ORCID: 0000-0001-7293-525X, Blackburn, Joanna, Edward, Karen-leigh, Stephenson, John and Ousey, Karen (2019) Emergency department nurse's attitudes towards patients who self-harm: A metaanalysis. International Journal of Mental Health Nursing, 28 (1). pp. 40-53. ISSN 1445-8330

It is advisable to refer to the publisher's version if you intend to cite from the work. http://dx.doi.org/10.1111/inm.12550

For more information about UCLan's research in this area go to http://www.uclan.ac.uk/researchgroups/ and search for <name of research Group>.

For information about Research generally at UCLan please go to http://www.uclan.ac.uk/research/

All outputs in CLoK are protected by Intellectual Property Rights law, including Copyright law. Copyright, IPR and Moral Rights for the works on this site are retained by the individual authors and/or other copyright owners. Terms and conditions for use of this material are defined in the policies page.

\section{CLoK}

Central Lancashire online Knowledge www.clok.uclan.ac.uk

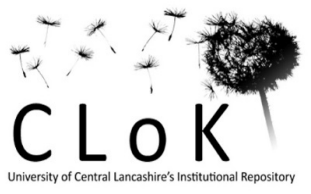




\begin{abstract}
Self-harm is a major challenge to public health. Emergency Department (ED) nurses treat significant proportions of patients with self-harm injuries and positive therapeutic patient-nurse interactions are imperative to the physical and psychological outcome of this vulnerable patient group. Research, both nationally and internationally suggests that treating those with self-harm injuries is emotionally challenging and ambivalence, powerlessness and ineffectiveness, are commonly manifested in negative attitudes towards these patients. Following the PRISMA guidelines, this systematic review with meta-analyses examined the attitudes of ED nurses towards patients who self-harm, based on currently available evidence. The following databases were searched: CINAHL complete; Medline complete; PsycARTICLES; PsycINFO; The Allied and Complementary Medicine Database; Health Source: Nursing/Academic Edition; PsycEXTRA; Psychology and Behavioural Sciences Collection. Clinical trials registries for ongoing and unpublished studies, and scanned reference lists of relevant reports to identify additional studies, were also searched. Five studies were included in the metaanalysis. The Self-Harm Antipathy Scale (SHAS) was used as an outcome in two studies appropriate for meta-analysis. The Attitudes Towards Deliberate Self-Harm (ADSHQ) scale was used as an outcome in three studies appropriate for meta-analysis. Results demonstrated limited empathy and negativity towards patients who self-harm, indicating a requirement for education and supervision of ED staff, where the SHAS or the ADSHQ can be used to monitor attitude change. Self-harm educational content for ED staff should include areas of knowledge building including: explanations and causes of self-harm; range, forms and functions of self-harm; staff responses to self-harm; assessment, management and interventions; professional practice issues.
\end{abstract}

Keywords: Attitudes, Emergency Department, Meta-Analysis, Self-Harm, 


\section{Introduction and rationale}

Self-harm is a significant challenge for public health and is at the forefront of the Government's initiative for preventing suicide in England (DOH 2017), in Australia (AlHW 2017) and in the United States of America (USA) (DH\&HS 2012), to name a few countries. Defined as 'intentional selfpoisoning or self-injury, irrespective of the nature of motivation or degree of suicidal intent' (RCP 2010), self-harm can include behaviours such as cutting, burning, biting and substance abuse; typically in response to stress or trauma, or as a coping mechanism. Self-harm can present as a behaviour in its own right, or co-exist with mental health disorders; for example, mood disorders, eating disorders and borderline personality disorder (NHS 2014). There are over 200,000 hospital attendances for self-harm per year in England: the highest incidence rates in Europe (DOH 2017); and these rates are increasing. Indeed, in a recent UK-based population cohort study using data from several data collection methods including electronic health records from 674 general practices, hospital episode statistics (HES) and Office for National Statistics (ONS) mortality records, found that between 2001-2014, the incidence of self-harm increased markedly in girls aged 10-19 years old to 37.4 per 10 000; an increase in incidence rate of $68 \%$. The corresponding rate in boys of the same age was 12.3 per 10000 (Morgan et al. 2017). Self-harm is a problem internationally. In Australia, prevalence rates are estimated at $17 \%$ and $12 \%$ for females and males, aged between 15 and 19 years respectively (Martin et al. 2010). In the USA it has been estimated that almost $4 \%$ of the population engage in self-harm behaviour (Klonsky et al. 2003). Despite being distinguishable by motivational intent, self-harm and suicide are intrinsically linked, and there is a compelling relationship between the two. It is predicted that one in 25 patients presenting to emergency departments for self-harm will die by suicide within the next 5 years, demonstrating the importance of this area in healthcare to save lives (Carroll et al. 2014).

Although the ED is often the gateway to people receiving treatment for self-harm injuries, many people who self-harm do so in the privacy of their own home (Madge et al. 2008) and several studies have focused on understanding the extent of self-harm in the community setting. For example, a recent study focusing on the prevalence of self-harm in the community in a sample of 309 adolescents aged 13-18 in England, found prevalence rates for self-harm of 15.5\% (Morey et al. 2017). In another study, Madge et al. (2008) examined the prevalence of deliberate self-harm in the community in seven countries through the Child and Adolescent Self-harm in Europe (CASE) Study. In this study, over 30,000 young people completed a school-based lifestyle and coping questionnaire in the classroom, designed to assess an individual's self-harm behaviour, health and lifestyle and psychological and emotional characteristics. Respondents were also asked about their last episode of self-harm and to describe their method of self-harming behaviour. The results indicated that overall, $8.9 \%$ of females and $2.6 \%$ of males reported an episode of self-harm in the past month and $13.5 \%$ of females and $4.3 \%$ of males reported an episode of self-harm during their lifetime. There were also differences across the different countries with participants from Australia reporting the highest rates of self-harm (11.8\%) in the past year compared to those from the Netherlands who reported the lowest rates at $3.6 \%$. Self-cutting was the most common method of self-harm at $55.9 \%$ of self-harm episodes followed by overdose, which was the primary method of self-harm in $22.3 \%$ of respondents. Research has also shown that patients often have increased attendances at their GP surgery prior to completing suicide, which could be indicative of the patients increased suffering and distress of managing their self-harm behaviour (Pearson et al. 2009).

\section{Staff attitudes to self-harm}

The scale of self-harming behaviour and the obvious impact that negative attitudes can have on effectiveness and quality of care has yielded several literature reviews designed to understand the 
influences of staff attitudes concerning self-harm. Saunders et al. (2012) conducted a systematic review of the international literature focusing on staff attitudes, and consistently found that nursing staff across several countries, including the UK, Australia, Sweden, Finland, Brazil and Taiwan, hold negative attitudes towards people who self-harm. This manifested in typically reported emotional responses including frustration, anger and hostility. In a review of the qualitative literature investigating the knowledge and perceptions of paramedics and emergency care staff towards patients who self-harm, Rees et al. (2014) concluded that staff working in acute settings experienced higher levels of negativity towards patients who self-harm, attributable to inefficient training and education around how to manage these patients, particularly in relation to their psychological needs. McHale and Felton (2010) conducted a thematic analysis of the literature focusing on the factors affecting health care professionals' attitudes towards self-harm and described how a fundamental factor in the development and maintenance of negative attitudes was a lack of training and education; whilst positive attitudes were attributable to being knowledgeable about self-harm. Similarly, Karman et al (2014) conducted a literature review of nurses' attitudes towards self-harm in nursing practice. Whilst many of the reviewed studies demonstrated the presence of both positive and negative staff attitudes, factors including the age of the nurses, gender, experience and education and training were pivotal in impacting the development and maintenance of negative attitudes towards these patients. Empathetic attributes have been evidenced in nurses who are older, more qualified and have had more experience of interacting with patients who self-harm, supporting an understanding that knowledge, experience and confidence can yield positive attitudes towards treating these patients (McCann et al. 2007, McCarthy \& Gijbels 2010). For example, Cleaver et al. (2014) found that nursing experience, rather than age or gender, elicited more positive attitudes towards young people who self-harm.

\section{Staff Attitudes and Antipathy Questionnaires}

Disparities in the findings of the attitudinal beliefs of nursing staff towards self-harm have supported the development of several standardised measures to assess this concept. Two of the most extensively applied tools include the Attitudes Towards Deliberate Self-harm Questionnaire (ADSHQ) (McAllister et al. 2002a) and the Self-harm Antipathy Scale (SHAS) (Patterson et al. 2007). The ADSHQ utilises four domains to focus on nursing attitudes towards self-harm, including: confidence in assessment and referral; effectiveness at dealing with clients; empathy; and ability to cope with legalities that govern practice. Participants scoring highly on this scale (scores between 83 and 132) are suggested to possess positive attitude towards those who self-harm and the care they are providing to this patient group, whilst low scores (scores between 33 and 82) are indicative of negative attitudes. The Self-harm Antipathy Scale (SHAS) (Patterson et al. 2007) comprises 30 statements about people who self-harm and rather than categorise respondents into possessing positive or negative attitudes, the scale reflects the variation in attitudes at the individual level. Respondents indicate to what extent they agree with a statement on a 7-point Likert scale ('strongly agree' to 'strongly disagree' with an 'undecided' midpoint). Possible scores using this scale range from 30, which is indicative of low antipathy, to 210 , reflecting high antipathy. Antipathy is defined as a negative individual attitude towards people who self-harm, developed through previous negative experiences with people from this patient group. Thus, the person who self-harms is subjected to pre-existing negative cognitions and rejecting behaviour from staff, developed through previous negative experiences (Patterson et al. 2007). Both these measures have identified components that influence and contribute to the development and maintenance of attitudes. For example, McAllister et al. (2002a) employed the ADSHQ and found no significant relationship between attitudes, confidence in treating patients who self-harm and nursing experience; suggesting that negative attitudes are not specifically reflective of an absence of exposure to these patients. 
However, Friedman et al. (2006) found that negative attitudes and emotions of anger towards patients with laceration injuries were evident in nursing staff with more nursing experience, but without any formal training for treating patients with self-harm. Patterson et al. (2007), who examined the concept of antipathy using the SHAS, found that general nurses evidenced significantly greater levels of antipathy than mental health nurses, and those who had received some education around approaches to self-harm. Although a gender effect was not statistically significant, females tended to exhibit greater antipathy than males, as did those respondents who were more experienced. Dickinson and Hurley (2011) used the SHAS to explore antipathy in a group of registered and unregistered nurses working in a young offenders' institute and forensic unit, finding that general nurses who had been practicing for a significant length of time exhibited greater levels of antipathy than unregistered nurses or those who had some mental health experience. Education in self-harm also contributed to lower levels of antipathy, suggesting that a focus on training and education could contribute to more positive attitudes towards people who self-harm. These questionnaires have been used in variety of settings, but this paper focuses on the analysis of use of these within the ED.

\section{Emergency Department}

Data collected from Hospital Episode Statistics Accident and Emergency Attendances in England (from 2014 to 2015) demonstrated that patients with self-harm injuries form one of the primary patient groups for ED attendance; accounting for $0.6 \%(110,847)$ of all recorded ED presentations during this time and self-laceration has been found to account for $5-10 \%$ of all self-harm presentations to ED in the UK (Hawton et al. 2002). Repeated self-harming is common in the ED (HSCIC 2013, Vedsted et al. 2004) and can represent a precursor to suicide. Importantly, suicide is significantly greater in patients with repeated episodes of self-harm than in those presenting on one occasion (Zahl \& Hawton 2004). In Australia, between 1 and 9\% of all ED presentations are due to self-harm injuries (ACEM-RANZCP 2000). Similarly, in Northern Ireland, data published by The Public Health Agency (PHA) demonstrates that ED presentations for self-harm increased by $7 \%$ during 2012-2015 (HSC 2015). As many publications use the word self-harm to cover a variety of methods on the continuum of self-harm, it is difficult to identify specifically self-injury/self-cutting/selflaceration. Babiker and Arnold (1997) state that self-injury includes physical damage to the skin: cutting burning, picking. Thus, presentations for self-cutting or laceration need further clarification within the self-harm publications. Self-harm may appear to exist on a continuum that may include suicidal behaviour and overdosing at the extreme end of the scale and more socially acceptable types of self-harm, such as sunbathing and waxing at the other (Babiker \& Arnold 1997). Evidence indicates that the most common method of self-harm for patients seeking treatment in the ED is self-poisoning. In one observational study conducted in five general hospitals in England over a 13year period, self-poisoning accounted for almost $75 \%$ of self-harm (Geulayov et al., 2016), with selfcutting being the second most commonly reported method of self-harm, accounting for $25 \%$ of all episodes. Similar incidence rates have been reported in Northern Ireland (Northern Ireland Registry of Self-Harm, 2013-2014), with drug overdose and self-cutting accounting for $73.7 \%$ and $23.8 \%$ of 8453 presentations of self-harm, respectively. Indeed, research suggests self-cutting is particularly common amongst adolescents (Morey et al., 2017).

Research both nationally and internationally suggests that emergency care nurses find treating patients who self-harm emotionally challenging. Ambivalence, powerlessness and helplessness are 
commonly manifested in the development of negative attitudinal beliefs towards these patients (Anderson et al. 2003, Conlon \& O'Tuathail 2012). A lack of staff knowledge and understanding of how to treat the psychological mechanisms of self-harm also contribute towards the destructive belief that patients are attention-seeking and manipulative (Conlon \& O'Tuathail 2012), which could contribute to the development and maintenance of a negative attitude towards these patients.

Although self-cutting or laceration is not the most commonly reported method of self-harm in the ED, cutting appears to pull a more negative response from staff. Friedman et al (2006) focused specifically on cutting and found that staff had more fear due to lack of knowledge about why people cut themselves. It seems that physical external damage to the self can cause staff to become more emotional and consequently have more challenges managing their own internal experience (Rayner \& Warne, 2015). This has been reported in a wide variety of areas of practice but continues to be repeatedly reported by people who self-harm in the emergency department.

Friedman et al. (2006) focused on examining ED nursing staff perceptions towards patients who selfharmed through laceration, using the researchers' own attitude scale developed through focus groups. Although self-harm through laceration was recognised as being a serious issue, many respondents did not feel knowledgeable enough to effectively treat this patient group, contributing to their negative attitudes towards them. Patients were described as 'attention-seeking', causing staff to feel frustrated, which was not related to nursing experience or training. Interestingly, greater experience of working in the ED was associated with increased anger towards patients who selfharmed and a perception that they were mentally ill. However, despite the findings from Friedman et al. (2006), people who self-harm by laceration often do not have a mental illness per se and this belief can have a negative effect on health care professional's ability to connect with individuals who self-harm and truly empathise with the patient on an individual level. The finding by Friedman et al. (2006) may be reflective of the pressures of working in the ED environment and a belief that these patients place unnecessary demands on an already stretched service. Operationally, the ED is not typically prepared to adapt to the complex physical and emotional needs of patients who self-harm. Nursing staff rarely have the time to devote to patients with psychological symptoms and with significant focus placed on treating the physicality of a patient's condition, it is likely that staff feel patients do not receive the level of care they need, and this could contribute to the development of negative attitudes. This is reinforced by the experiences of patients who report being subjected to stigmatising behaviour from staff, feelings of worthlessness and not feeling 'valued' (Cerel et al. 2006, Giandinoto \& Edward 2014).

In another paper, McCarthy and Gijbels (2010) investigated the beliefs of 71 ED trauma nurses in Ireland towards deliberate self-harm using an adapted version of the Attitudes Towards Deliberate Self-Harm Questionnaire (ADSHQ) to understand if factors including age, gender, qualifications, nursing experience and previous experience of mental health education were associated with attitude formation. Findings suggested that generally, nurses held positive attitudes towards patients who self-harm. Nurses who were older and who held postgraduate qualifications had more positive attitudes than those nurses who were younger or had hospital training. Although not statistically significant, the results indicated towards more experienced nurses having more positive attitudes. However, those nurses with more than 16 years of nursing experience in the ED exhibited the opposite effect and did not hold more positive attitudes towards patients who self-harm.

UK NICE guidelines (NICE 2016) recommend that patients presenting in the ED with self-harm injuries should be provided with an initial psychological assessment followed by continuing support that integrates multi-disciplinary collaborations between mental health services; however, evidence suggests that many patients do not receive this level of care. In a large-scale observational study 
examining epidemiology and trends in non-fatal self-harm in three centres in England, Geulayov et al. (2016) found that between 2000-2012 there were 84, 378 episodes of self-harm, 58.6\% of which were by females. Of concern, is that in only $53.2 \%$ of self-harm episodes did patients receive a psychological assessment, suggesting that patients presenting in the ED do not receive the psychological support they require to manage their condition.

Self-harm is concomitant with significant distress and suffering, and the treatment and care patients receive can have a profound influence on their prospect of recovery and long-term outcomes.

Emergency healthcare professionals are largely considered the initial provider of treatment and care to patients who self-harm, and these therapeutic interactions are likely to have a significant bearing on the physical and psychological outcome of this vulnerable patient group.

A variety of literature reviews have been completed, focusing on attitudes of different groups of staff who engage with people who self-harm. The tendency to bring together all methods of selfharm can lead to confusing and contradictory conclusions. Some review papers have focused on ED staff attitudes. Whilst there is evidence to support both positive and negative attitudinal attributes, the extent to which these attitudes exist and the specific factors that may influence their development is still unclear. This is important, as the attitudes of nursing teams working in the ED are likely to have an influence on the patient experience and outcomes and potentially the quality of care. This review aims to understand the extent to which differing attitudinal beliefs in ED nurses exist and is the first systematic review and meta-analysis to examine the attitudes of Emergency Department Nurses towards patients who self-harm based on the current available evidence. The research question guiding the meta-analysis was - 'What are Emergency Department Nurses attitudes towards people who self-harm?'

\section{Methods}

\section{Search Strategy}

The following databases were searched for relevant studies: CINAHL complete; Medline complete; PsycARTICLES; PsycINFO; The Allied and Complementary Medicine Database; Health Source: Nursing/Academic Edition; PsycEXTRA; Psychology and Behavioural Sciences Collection. Clinical trials registries for ongoing and unpublished studies, and scanned reference lists of relevant reports to identify additional studies, were also searched. Please see box 1 (search string) for further details. Two review authors (KO \& GR) independently assessed study selection; disagreement occurring during selection was resolved by discussion between the review authors.

\section{Inclusion Criteria}

No restrictions were made with respect to date of publication and quantitative papers published up to 2018 were included if they met the inclusion criteria to allow for the return of all studies that have been undertaken on the topic. Only papers written in English and focusing on the Emergency Department were included (see Box 2 for full details of inclusion criteria). Studies published in duplicate were included once. An additional search with wounds added 11 papers (see Figure 1); of which 2 were included for full read. A Preferred Reporting Items for Systematic Reviews and MetaAnalyses (PRISMA) flow chart to summarise the selection of studies was completed (see Figure 1).

Insert box 1 here 
Insert box 2 here 
INSERT FIGURE ONE HERE 


\section{Meta-analysis methods}

Presentation of our meta-analyses results follows a standard format. Relevant $\mathrm{p}$-values were reported for all analyses (including those for the Z-test for overall effect and those for the test of heterogeneity in all cases. We followed exactly the PRISMA guidelines for the reporting of metaanalyses results as summarised in, for example, BMJ 2009;339:b2700; and similar reporting to ours is found in many systematic reviews published by the Cochrane Collaboration.

Prevalence (single proportion) meta-analyses were conducted to assess the antipathy of nursing staff towards self-harm patients. Separate meta-analyses were considered for studies using different scales, to reduce design heterogeneity. A minimum of 2 studies using a given scale were needed for inclusion in a prevalence meta-analysis.

Comparative meta-analyses were also conducted comparing sub-groups of participants. Again, separate meta-analyses were considered for studies using different scales. A minimum of 2 studies using a given scale, and using the same sub-groups, were needed for inclusion in a comparative meta-analysis.

All outcomes in the prevalence meta-analyses were continuous, expressed as the mean overall scale score of participants on a particular scale, with associated $95 \%$ confidence intervals (Cls). All outcomes in the comparative meta-analyses were also continuous, expressed using unstandardized weighted mean differences (WMDs) between groups, with associated $95 \% \mathrm{Cls}$, using the inverse variance method. All results were displayed in forest plots. Funnel plots were not constructed due to the limited number of studies included in the meta-analysis. Random effects models were conservatively used for all analyses.

Statistical heterogeneity was assessed using Cochran's $Q$ statistic which approximately follows a $\chi^{2}$ distribution on $n-1$ degrees of freedom, and the $I^{2}$ statistic. An $I^{2}$ estimate of around $75 \%$ accompanied by a significant result from the $\chi^{2}$ statistic was interpreted as evidence of substantial levels of statistical heterogeneity. The corresponding between-study variance of the intervention effect $\left(\tau^{2}\right)$ was also derived. A Z-test for overall effect was also conducted in all cases; however, for the prevalence meta-analyses, it was expected that the scores reported by participants would be significantly different to zero.

Sub-group analyses and meta-regressions were not planned a priori or subsequently undertaken.

Meta-analyses were conducted using Stata statistical software (Version 14 I/C).

\section{Results}

The meta-analyses examined five studies (782 participants) focusing on staff attitudes in the ED when working with people who self-harm (see Table 1 for the list of included studies). The metaanalysis results demonstrated mean overall scores of 78.1 for the SHAS and 68.1 for the ADSHQ. We believe this method of presentation of numbers of cases is logical (and in line with customary procedures): the studies for inclusion are identified first, based on various criteria. They are then assessed for suitability for inclusion in one or more meta-analyses on much more narrowly defined criteria. It is potentially misleading to consider the meta-analyses as "separate".

\section{INSERT TABLE ONE HERE}

Meta-analysis 1: prevalence analysis on SHAS 
The Self-Harm Antipathy Scale (SHAS) was used as an outcome in 2 studies. A single-proportion random effects meta-analysis conducted on this outcome determined that a synthesised estimate for the mean overall score on this scale was 78.1 ( $95 \% \mathrm{Cl} 69.1$ to 87.1 ). A $Z$-test for overall effect revealed strong evidence that this proportion was non-zero $(Z=17.1, p<0.001)$. Individual estimates ranged for the proportion ranged from 73.6 (Conlan 2010) to 82.7 (Patterson et al. 2007).

Cochran's $Q$ test revealed strong evidence for statistical heterogeneity $\left(\chi_{(1)}^{2}=24.0 ; p<0.001\right)$. The $I^{2}$ statistic was $95.8 \%$, indicating substantial statistical heterogeneity. The $\tau^{2}$ statistic (between-study variance) was calculated to be 40.2 ; reflecting a high proportion of variance between studies compared to within studies.

Results are summarised in a forest plot (Figure 2).

\section{INSERT FIGURE TWO HERE}

Meta-analysis 2: prevalence analysis on $A D S H Q$

The Attitudes Towards Deliberate Self-Harm (ADSHQ) scale was used as an outcome in 3 studies. A single-proportion random effects meta-analysis conducted on this outcome determined that a synthesised estimate for the mean overall score on this scale was 68.1 ( $95 \% \mathrm{Cl} 64.6$ to 71.6$)$. A Z-test for overall effect revealed strong evidence that this proportion was non-zero $(Z=38.2, p<0.001)$. Individual estimates ranged for the proportion ranged from 64.7 (McAllister 2002) to 70.6 (McCarthy 2009).

Cochran's $Q$ test revealed strong evidence for statistical heterogeneity $\left(\chi_{(2)}^{2}=69.5 ; p<0.001\right)$. The $I^{2}$ statistic was $97.1 \%$, indicating substantial statistical heterogeneity. The $\tau^{2}$ statistic (between-study variance) was calculated to be 9.21 , reflecting a high proportion of variance between studies compared to within studies.

Results are summarised in a forest plot (Figure 3).

\section{INSERT FIGURE 3 HERE}

\section{Meta-analysis 3: comparative analysis on gender amongst SHAS-based studies}

Two studies using the SHAS as an outcome recorded scores for male and female participants separately. Conlan et al. (2010) and Patterson et al. (2007) found female participants to report higher scores than male participants. The synthesized estimate for the mean difference between females and males was $-6.72(95 \% \mathrm{Cl}-14.27$ to 0.84$)$, with the higher estimate for females. A Z-test for overall effect revealed insufficient evidence that this difference was statistically significant $(Z=1.74, p=0.081)$.

Cochran's $Q$ test revealed no evidence for statistical heterogeneity $\left(\chi^{2}(1)=1.513 ; p=0.216\right)$. The $I^{2}$ statistic was $34.8 \%$, indicating limited statistical heterogeneity. The $\tau^{2}$ statistic (between-study variance) was calculated to be 12.5 , reflecting a fairly low proportion of variance between studies compared to within studies.

Results are summarised in a forest plot (Figure 4).

INSERT FIGURE 4 HERE 
Two studies using the SHAS as an outcome recorded scores for novice practitioners (those with 10 years or fewer experience with self-harming clients) and experienced practitioners (those with over 10 years' experience with self-harming clients) participants separately. Conlan et al. (2010) found experienced practitioners to report higher scores than novice practitioners. Patterson et al. (2007) found novice practitioners to report higher scores than experienced practitioners. The synthesized estimate for the mean difference between novice and experienced practitioners was $-1.02(95 \% \mathrm{Cl}$ 6.23 to 4.19 ), with the higher estimate reported for novice practitioners. A Z-test for overall effect revealed no evidence that this difference was statistically significant $(Z=0.38, p=0.702)$.

Cochran's $Q$ test revealed no evidence for statistical heterogeneity $\left(\chi_{(1)}^{2}=0.40 ; p=0.525\right)$. The $\mathrm{I}^{2}$ statistic was $0.0 \%$, indicating no statistical heterogeneity; with a corresponding $\tau^{2}$ statistic (betweenstudy variance) of 0.00 .

Results are summarised in a forest plot (Figure 5).

\section{INSERT FIGURE 5 HERE}

For the SHAS, previous scores reported by Patterson et al. (2007) for the overall scale were 82.7. A higher score of 93.2 was found for general/adult nurses, whilst nurses who primarily worked in the ED had a score of 93.6, indicative of higher levels of antipathy in this staff group. Despite the scores reported here being slightly lower than Patterson et al. (2007) overall scores for the multiprofessional's groups, the results nevertheless reflect the existence of some level of antipathy towards people who self-harm and suggests that the low antipathy scores held by the participants is suggestive of low levels of negative beliefs. The overall ADSHQ score of 68 was slightly higher than McAllister et al. (2002a) who had an overall score of 65.16 with general/adult nurses working in emergency departments This demonstrates the existence of some level of negative staff attitudes towards people who self-harm. As these scales do not appear to have been used in public populations we do not know how high these are in relation to other non-health professional populations.

\section{Discussion}

The findings of this meta-analysis demonstrate mixed attitudes towards people who self-harm, with the presence of both negative attitudes and the existence of some level of antipathy towards patients from ED staff. Scores in the AQSHQ were indicative of an existence of negative attitudes towards people who self-harm, whilst scores from the SHAS were suggestive of some level of antipathy towards these patients, despite it not being predominantly negative. Understanding the attitudes of emergency care staff towards patients who self-harm using validated scales is an emerging area of study and consequently there were limited papers published using these specific scales. Additionally, the two scales focus on different aspects of attitudinal beliefs towards those who self-harm in different healthcare professional populations. The ADSHQ focuses on factors including confidence in assessment and referral, health systems, interventions, staff empathy, beliefs and attitudes and was developed specifically for staff working in emergency departments. The SHAS focuses more on staff antipathy/empathy, emotions, beliefs and attitudes about selfharm, interventions and skills and was developed for use within mental health settings, even though the original sample had a variety of different staff groups from mental health, learning disability and adult/general nursing settings. 
Although the findings from the SHAS were not indicative of extreme antipathy towards patients who self-harm, they did point to the presence of some level of antipathy (a mean score of 120 on the SHAS scale would correspond to "neutral" responses to each item; the obtained score of 78 points corresponds to an attitude approximately halfway between neutrality and extreme disagreement with a negatively worded statement) and low antipathy in ED staff towards people who self-harm. However, it is unclear to what extent the average scores on either of the two scales are reflective of attitudinal beliefs. Females reported higher antipathy than males; this finding was not significant but nonetheless may be suggestive of less empathetic attitudes towards these patients by female staff members. The direction of effect, and level of significance of the synthesized estimate is consistent with the estimate of Patterson et al. (2007b). However, the finding could reflect most participants in the included studies being female (although this is often the demographic for staff in healthcare settings); leading to greater uncertainty in the calculated estimates for the male participants. The meta-analysis also showed that more experienced staff tended to score higher than less experienced staff; suggestive of greater levels of antipathy; although this result was also not statistically significant. The direction of effect of the synthesized estimate is also consistent with the findings from Patterson et al. (2007). However, consistent with both Conlan et al. (2010) and Patterson et al. (2007), this overall finding was also non-significant, suggesting the results could be ascribed to sampling variation rather than any actual differences in the dimensional differences of attitudinal beliefs. Healthcare professionals with direct patient-specific experience, for example mental health nurses, have been found to hold positive attitudes towards self-harming patients, suggesting that regular interactions with patients who self-harm encourage more compassionate behaviours (McHale and Felton, 2010). Indeed, the research discussed in this paper does suggest that increased training and education on how to treat patients who self-harm encourages more positive attitudes. Negative staff attitudes have been found to have a substantial effect on the patient experience of care and a survey conducted by the Royal College of Psychiatrists in Ireland found that many patients described how they were subjected to disapproving and discriminating behaviours from staff attributable to their self-harm (Palmer, Strevens and Blackwell., 2007). Although factors including nursing age, gender, experience and education and training have been found to influence the maintenance of negative attitudes towards patients who self-harm in healthcare professionals more generally, (Karman et al., 2014), this meta-analysis only demonstrated a tendency for some of these factors to be influential.

Evidence suggests that a fundamental factor in the development and maintenance of negative attitudes is limited training and education, with knowledge and awareness being key elements of the development of positive attitudes towards self-harm (McHale \& Felton 2010). The results of this meta-analysis suggest that although ED staff do not appear to hold extreme negative attitudes towards people who self-harm, training and education and supervision of ED staff, where either the SHAS or the ADSHQ questionnaires could be used to monitor change in staff attitudes thus measuring the impact of educational supports provided, may be advantageous and contribute towards more positively held beliefs towards this patient group. Indeed, both McAllister et al. (2009) and Patterson et al. (2007) went on to develop educational materials and documented attitudinal improvement in staff towards self-harm.

\section{Limitations}

Whilst all relevant studies have been included in this review, there were some limitations. For example, the studies that used the ADSHQ and SHAS questionnaires to assess the attitudes of emergency care staff towards patients who self-harm varied in the sub-scales of these scales that were utilised. Moreover, the two scales were also non-compatible and focused on different aspects 
of attitudinal beliefs towards self-harm. Several researchers created their own questionnaires or used suicide-focused scales, which were outside the focus of this meta-analysis.

\section{Recommendations and Conclusions}

From the findings of the meta-analyses, education provided to ED staff with respect to self-harm care for patients who present to the ED should be the norm. Improvements in the educational preparedness of staff in EDs to care for those who self-harm, together with support such as clinical supervision, is needed to build staff confidence in working with this patient population. It remains unclear if staff attitudes in ED alter towards people who self-injure, as opposed to arguably more commonly understood methods of self-harm such as overdosing. The papers and questionnaires in this meta-analyses all combine different methods of self-harm. Therefore, further research is required to identify if staff attitudes are more negative towards people who self-injure, rather than other methods of self-harm such as overdosing.

Given the presence of both antipathy and empathy in the interactions of staff with patients who selfharm, greater exposure of staff to building the therapeutic alliance with patients in the context of a non-judgmental approach to care may offer a means to reduce labeling and potentially reduce any antipathy staff may develop with regards to this patient group. Knowledge and attitudes are significant contributors to care provided in the demanding environment of the ED. Understanding through evaluation, using reliable and valid tools such as the SHAS or the ADSHQ questionnaires, can guide policy-makers in hospitals in decisions related to educational requirements of staff, and the impacts of education provided regarding caring for people who self-harm.

Despite these limitations, this meta-analysis demonstrated continuing high levels of negative staff attitudes in ED staff when working with people who self-harm. In previous literature reviews on attitudes to self-harm, education was regarded as vital for staff for improvements in knowledge, confidence and attitudes; and in turn improved personal perceived effectiveness. An important note: the UK NICE guidelines on self-harm recommend compulsory education for all staff working with people who self-harm, although this is not yet standard practice in healthcare organisations. There are clusters of ongoing work in Australia (McAllister et al. 2002b, McCann et al. 2006, McCann et al. 2007), the UK (Conlon \& O'Tuathail 2012, Egan et al. 2012, Friedman et al. 2006, Mackay \& Barrowclough 2005, McCarthy \& Gijbels 2010, Patterson et al. 2007) and the Republic of Ireland (McCarthy \& Gijbels 2010; Conlon \& O'Tuathail 2012) but very little research has been published from other countries on emergency department staff attitudes and self-harm.

\section{Relevance to Clinical Practice}

The authors suggest the self-harm educational content for ED staff should include key areas of knowledge building such as: explanations and causes of self-harm and suicide; range, forms and functions of self-harm; staff responses to self-harm; assessment, management and interventions (including triage training in EDs); professional practice issues. Education should include ongoing clinical supervision where staff can explore their attitudes and beliefs in a non-threatening environment. The authors of this paper would also add the following educational material to provide a fully integrated physical and psychological social education: exploration of the interpersonal processes for staff when working with people who self-harm (Rayner \& Warne 2016, Rayner et al. 2005); empathy, therapeutic alliance and communication educational and skills training; and as indicated by Ousey et al. (2014): wound care/physical care whilst providing emotional wellbeing support. 


\section{References}

ACEM-RANZCP (2000) Guidelines for the Management of Deliberate Self Harm in Young People. Australasian College for Emergency Medicine (ACEM) and The Royal Australian and New Zealand College of Psychiatrists (RANZCP), Melbourne Vic Australia.

AlHW (2017) Australia's welfare 2017 (Welfare AloHa ed.). AlHW, Canberra, Australia, p. 441.

Anderson M, Standen P \& Noon J (2003): Nurses' and doctors' perceptions of young people who engage in suicidal behaviour: a contemporary grounded theory analysis. International journal of nursing studies 40, 587-597.

Babiker G \& Arnold L (1997) The language of injury: Comprehending self-mutilation. Wiley-blackwell.

Carroll R, Metcalfe C \& Gunnell D (2014): Hospital presenting self-harm and risk of fatal and nonfatal repetition: systematic review and meta-analysis. PLoS One 9, e89944.

Cerel J, Currier GW \& Conwell Y (2006): Consumer and family experiences in the emergency department following a suicide attempt. Journal of Psychiatric Practice ${ }^{\circledR} 12,341-347$.

Cleaver K, Meerabeau L \& Maras P (2014): Attitudes towards young people who self-harm: age, an influencing factor. Journal Of Advanced Nursing 70, 2884-2896.

Conlon M \& O'Tuathail C (2012): Measuring emergency department nurses' attitudes towards deliberate self-harm using the Self-Harm Antipathy Scale. International Emergency Nursing 20, 3-13.

DH\&HS (2012) National strategy for suicide prevention: Goal and objectives for action 2012. US Department of Health \& Human Services, Washington DC USA.

Dickinson T \& Hurley M (2011): Exploring the antipathy of nursing staff who work within secure healthcare facilities across the United Kingdom to young people who self-harm. Journal of Advanced Nursing 68, 147-158.

DOH (2017) Preventing suicide in England: Third progress report on the cross-government outcomes strategy to save lives. Department of Health, UK. Available at: https://www.gov.uk/government/uploads/system/uploads/attachment data/file/582117/S uicide report 2016 A.pdf (accessed 6 December 2017).

Egan R, Sarma KM \& O'Neill M (2012): Factors influencing perceived effectiveness in dealing with self-harming patients in a sample of emergency department staff. The Journal Of Emergency Medicine 43, 1084-1090.

Friedman T, Newton C, Coggan C, Hooley S, Patel R, Pickard M \& Mitchell AJ (2006): Predictors of $A \& E$ staff attitudes to self-harm patients who use self-laceration: influence of previous training and experience. Journal Of Psychosomatic Research 60, 273-277.

Geulayov G, Kapur N, Turnbull P, Clements C, Waters K, Ness J, Townsend E \& Hawton K (2016): Epidemiology and trends in non-fatal self-harm in three centres in England, 2000-2012: findings from the Multicentre Study of Self-harm in England. BMJ open 6, e010538.

Giandinoto JA \& Edward KL (2014): Challenges in acute care of people with co-morbid mental illness. British Journal of Nursing 23, 728-732.

Hawton K, Rodham K, Evans E \& Weatherall R (2002): Deliberate self harm in adolescents: self report survey in schools in England. BMJ 325, 1207-1211.

HSC (2015) Northern Ireland Registry of Self-harm - Three-year report, 2012/13 to 2014/15. HSCPublic Health Agency, Ireland. Available at: http://www.publichealth.hscni.net/sites/default/files/NIRSH\%203\%20year\%20report\%2014. 11.06.pdf (accessed 5 December 2017).

HSCIC (2013) Mental Health Bulletin: Annual report from MHMDS returns - England 2012/2013. Health and Social Care Information Centre UK. Available at: http://www.hscic.gov.uk/catalogue/PUB12745/mhb-1213-ann-rep.pdf (accessed 6 December 2017).

Klonsky ED, Oltmanns TF \& Turkheimer E (2003): Deliberate self-harm in a nonclinical population: Prevalence and psychological correlates. American Journal of Psychiatry 160, 1501-1508. 
Mackay N \& Barrowclough C (2005): Accident and emergency staff's perceptions of deliberate selfharm: attributions, emotions and willingness to help. British Journal of Clinical Psychology 44, 255-267.

Madge, N. , Hewitt, A. , Hawton, K. , Wilde, E. J., Corcoran, . P., Fekete, S. , Heeringen, K. V., Leo, D. D. and Ystgaard, M. (2008), Deliberate self-harm within an international community sample of young people: comparative findings from the Child \& Adolescent Self-harm in Europe (CASE) Study. Journal of Child Psychology and Psychiatry, 49: 667-677. doi:10.1111/i.14697610.2008.01879.x

Martin G, Swannell SV, Hazell PL, Harrison JE \& Taylor AW (2010): Self-injury in Australia: a community survey. Medical Journal of Australia 193, 506.

McAllister M, Creedy D, Moyle W \& Farrugia C (2002a): Nurses' attitudes towards clients who selfharm. Journal Of Advanced Nursing 40, 578-586.

McAllister M, Creedy D, Moyle W \& Farrugia C (2002b): Study of Queensland emergency department nurses' actions and formal and informal procedures for clients who self-harm. International Journal Of Nursing Practice 8, 184-190.

McAllister M, Moyle W, Billett S \& Zimmer-Gembeck M (2009): 'I can actually talk to them now': qualitative results of an educational intervention for emergency nurses caring for clients who self-injure. Journal of Clinical Nursing 18, 2838-2845.

McCann T, Clark E, McConnachie S \& Harvey I (2006): Accident and emergency nurses' attitudes towards patients who self-harm. Accident and emergency nursing 14, 4-10.

McCann TV, Clark E, McConnachie S \& Harvey I (2007): Deliberate self-harm: emergency department nurses' attitudes, triage and care intentions. Journal Of Clinical Nursing 16, 1704-1711.

McCarthy L \& Gijbels H (2010): An examination of emergency department nurses' attitudes towards deliberate self-harm in an Irish teaching hospital. International Emergency Nursing 18, 2935.

McHale J \& Felton A (2010): Self-harm: what's the problem? A literature review of the factors affecting attitudes towards self-harm. Journal Of Psychiatric And Mental Health Nursing 17, 732-740.

Morgan C, Webb RT, Carr MJ, Kontopantelis E, Green J, Chew-Graham CA, Kapur N \& Ashcroft DM (2017): Incidence, clinical management, and mortality risk following self harm among children and adolescents: cohort study in primary care. BMJ 359.

NHS (2014) Mental Health Bulletin, Annual Report From MHMDS Returns, England - 2012-13. NHS, UK. Available at: http://digital.nhs.uk/catalogue/PUB12745 (accessed 6 December 2017).

NICE (2016) Surveillance report 2016 - Self-harm in over 8s: short-term management and prevention of recurrence (2004) NICE guideline CG16 and Self-harm in over 8s: long term management (2011) NICE guideline CG133. Available at:

https://www.nice.org.uk/guidance/cg133/resources/surveillance-report-2016-selfharm-inover-8s-shortterm-management-and-prevention-of-recurrence-2004-nice-guideline-cg16and-selfharm-in-over-8s-long-term-management-2011-nice-guideline-cg1332664201424/chapter/how-we-made-the-decision (accessed 5 April

Ousey K, Edward K-L \& Stephenson J (2014): Exploring quality of life, physical and psychosocial morbidity for patients with non-infected wounds: a pilot study. Wounds UK 10, 30-34.

Patterson P, Whittington R \& Bogg J (2007): Measuring nurse attitudes towards deliberate self-harm: the Self-Harm Antipathy Scale (SHAS). Journal Of Psychiatric And Mental Health Nursing 14, 438-445.

Rayner G \& Warne T (2016): Interpersonal processes and self-injury: a qualitative study using Bricolage. Journal Of Psychiatric And Mental Health Nursing 23, 54-65.

Rayner GC, Allen SL \& Johnson M (2005): Countertransference and self-injury: a cognitive behavioural cycle. Journal Of Advanced Nursing 50, 12-19.

RCP (2010) Self-harm, suicide and risk: a summary. Position Statement PS3/2010. July 2010. RCP, UK. Available at: https://www.rcpsych.ac.uk/pdf/PS03-2010x.pdf (accessed 6 December 2017). 
Rees N, Rapport F, Thomas G, John A \& Snooks H (2014): Perceptions of paramedic and emergency care workers of those who self harm: a systematic review of the quantitative literature. Journal Of Psychosomatic Research 77, 449-456.

Saunders KE, Hawton K, Fortune S \& Farrell S (2012): Attitudes and knowledge of clinical staff regarding people who self-harm: a systematic review. . Journal of Affective Disorders 139, 205-216.

Vedsted P, Fink P, Sørensen HT \& Olesen F (2004): Physical, mental and social factors associated with frequent attendance in Danish general practice. A population-based cross-sectional study. Social science \& medicine $59,813-823$.

Zahl DL \& Hawton K (2004): Repetition of deliberate self-harm and subsequent suicide risk: longterm follow-up study of 11583 patients. The British Journal of Psychiatry 185, 70-75. 
Box 1 - Search string

\#1 (MH "Injuries, Self-Inflicted") OR (MH "Self-Injurious Behavior") OR "self-harm" OR (MH "Self Mutilation Risk (Saba CCC)") OR (MH "Self Neglect")

\#3(MH "Attitude of Health Personnel") OR (MH "Health Personnel") OR (MH "Attitude to Illness") OR "health personnel attitude" OR (MH "Attitude to Mental Illness") OR (MH "Attitude to Risk")

\#3 S1 AND S2

An additional search included the word "wound" OR "self-inflicted wound" and was combined with S3

Box 2 - Inclusion/exclusion criteria for selected studies

\begin{tabular}{|l|l|l|}
\hline Feature & Inclusion Criteria & Exclusion Criteria \\
\hline Participants & $\begin{array}{l}\text { Any papers that report } \\
\text { attitudes/perceptions of staff in } \\
\text { the ED }\end{array}$ & Does not focus on ED staff \\
\hline Focus of Study & $\begin{array}{l}\text { Any papers that report self- } \\
\text { harm/self-injury }\end{array}$ & $\begin{array}{l}\text { Focuses on suicide } \\
\text { Does not mention self- } \\
\text { harm/injury } \\
\text { Focuses on mental health } \\
\text { settings }\end{array}$ \\
\hline Date of Publication & No date restrictions applied & Papers not written in English \\
\hline Language & Papers written in English & Literature Review \\
\hline Type of paper & Quantitative Research & \\
\hline
\end{tabular}


Table 1 - Studies selected for meta-analysis

\begin{tabular}{|c|c|c|c|c|}
\hline Title of Paper Included & Location & $\mathrm{N}$ & Sample & Tools \\
\hline $\begin{array}{l}\text { Conlon \& O'Tuathail (2010) Measuing } \\
\text { emergency department nurses' attitudes } \\
\text { towards deliberate self-harm using the Self- } \\
\text { Harm Antipathy Scale }\end{array}$ & Ireland & 87 & ED nurses & SHAS \\
\hline $\begin{array}{l}\text { McAllister, Creddy, Moyle \& Farrugia (2002) } \\
\text { Nurses' attitudes towards clients who self- } \\
\text { harm }\end{array}$ & Australia & 352 & ED nurses & ADSHQ \\
\hline $\begin{array}{l}\text { McCarthy \& Gijbels (2010) An examination } \\
\text { of emergency department nurses' attitudes } \\
\text { towards deliberate self-harm in an Irish } \\
\text { teaching hospital }\end{array}$ & Ireland & 68 & ED nurses & ADSHQ plus 4 subscales \\
\hline $\begin{array}{l}\text { Paterson, Whittington \& Bogg (2007b) } \\
\text { Measuring nurse attitudes towards } \\
\text { deliberate self-harm: the Self-Harm } \\
\text { Antipathy Scale (SHAS) }\end{array}$ & UK & 153 & $\begin{array}{l}\text { Health care } \\
\text { professionals } \\
\text { including staff } \\
\text { working in mental } \\
\text { health, ED, general } \\
\text { health and forensic } \\
\text { and learning } \\
\text { disabilities. }\end{array}$ & SHAS \\
\hline $\begin{array}{l}\text { Perboell, Hammer, Oestergaard, Konradsen } \\
\text { (2014) Danish emergency nurses' attitudes } \\
\text { towards self-harm - a cross sectional study }\end{array}$ & Denmark & 122 & ED nurses & Danish version of $A D S H Q$ \\
\hline
\end{tabular}

